\title{
Grammarly Investigation into EFL Writing Issues Involving Omani Learners
}

\author{
John Michael Villar Faller \\ Coordinator \\ College Research and Consultancy \\ Ibra College of Technology \\ Sultanate of Oman
}

\begin{abstract}
This paper is one of appraisal that dwells on EFL writing, albeit focused on Omani learners in particular. It used an electronic writing enhancement platform, the Grammarly, to identify the writing issues in two essays of Level 4 Foundation students. In six broad categories - Spelling, Grammar, Punctuation, Enhancement Suggestion, Sentence Structure and Style - the upper group had 3,551 issues clustered into 28 sub-categories while the lower group recorded 3,974 issues bundled into 27 sub-categories. Statistical Package for the Social Sciences was used to get the mean, standard deviation and significant difference between groups in terms of issues and sexes. It was found out that the writing issues between the two groups were significantly different with p-value of 0.016. Specifically, the writing issues means in Essay 1 at p-value of 0.001 was found to be significant. On the other hand, writing issues in Essay 2 has no significant difference with p-value of 0.965. Moreover, there is no significant difference in the writing issues between sexes as confirmed by the computed p-value of 0.557.
\end{abstract}

Keywords: electronic enhancement writing platform, writing issues, essay writing, grammarly, EFL

\section{Introduction}

Writing has been a frequented object of study among language scholars. Harmer (2007) perceives it as a series of procedures done in different stages to include drafting, editing, planning, and the final draft. It is further regarded as the process that entails planning, reflecting, and organizing ideas that learners must observe (Damianiet al., 2011), as required by some language courses. Writing effective essays in English, for instance, is an essential skill for EFL students to progress to higher levels wherein more writing demands are expected till they finish the Bachelor's degree. They must learn to write, and write to learn. Working with vocabulary and spelling, and on to the composition of longer texts, covers the learning-to-write notion (Evensen, 2006). It involves knowledge on syntax, sentence structures, style, and building up a text based on specific rhetorical-linguistic conventions of their chosen genre (Bazerman, Little et al., 2005). Since text types differ from one, discipline to another, or from course to course, one shouldlearn, if not master, the text types in the course one is enrolled in (Thaiss, 2001). Writing-to-learn regards writing for a tool in acquiring new knowledge, skills, and comprehension. One can use it to reflect, to reformulate issues, and to reproduce facts relative to an issue (Langer and Applebee, 1987). Commonly viewed as private to a student's own consumption, it is not accordingly for assessment (Dysthe, Hertzberg and Hoel, 2010). A writer, in an actual situation, could grapple with these simultaneously as all writing in EFL represents an "interaction of purposes" (Manchón, 2011a). But in the classroom, written outputs are handed in and evaluated to gauge the expected learning outcomes (Reid \& Kroll, 1995).

Writing is such a complex activity that requires a lot of cognitive and linguistic abilities. Suffering from the foreignness of the language used, moreover, the EFL learners commit a lot of errors when completing a particular essay. Studies conducted by Khansir et al. (2013), Kuar and Singh (2013), Chkotau (2011), Abusaeedi (2015), Chan (2010), Koroglu (2014), Sattayatham and Ratanapinyowong (2008), Darus and Ching (2009), Hourani (2008), and Uhrikova (2011) demonstrate the seriousness of the number of various errors found in written outputs of students in their paragraphs, letters, and essays. These studies made use of writing experts to identify the errors. However, the present study is different in that it made use of an electronic enhancementwriting platform available on the web known as Grammarly. Thus, using this platform, the study investigates the types of errors and significant differences between groups and sexes in the essays of Level 4 students. 
Developed by Grammarly, Inc. as a cloud-based (Kepes, 2015) English-language writing-enhancement platform, the software initially was released in late 2009 checking write-ups, with its plagiarism-detection and proofreading resources, against the more than 250 grammar rules. Grammarly automatically detects errors in grammar, word choice, punctuation, spelling, and style in writing. Its algorithms flag issues and likewise suggest corrections for grammar, style, spelling, punctuation, wordiness, and plagiarism, available as an app for both iOS and Android for a monthly payment, of course (Moore, 2018).

The present study aims to find out the writing issues and significant differences between groups and sexes of Level 4 Foundation students of the English Language Centre at Ibra College of Technology in two essays written during the mid-semester examination. The issues included spelling, grammar, punctuation, enhancement suggestion, sentence structure, and style check. The study attempts to answer the following questions:

1. What are the means of the upper and lower groups in Essay 1 - Division and Classification and Essay 2 Causes and Effects with respect to the issue on: (a) Spelling Correction; (b) Grammar; (c) Punctuation; (d) Enhancement Suggestion; (e) Sentence Structure; and (f) Style Check?

2. Is there a significant difference between the means of the upper and lower groups with respect to the issue on: (a) Spelling Correction; (b) Grammar; (c) Punctuation; (d) Enhancement Suggestion; (e) Sentence Structure; and (f) Style Check?

3. What are the means of the males and females in Essay 1 - Division and Classification and Essay 2 - Causes and Effects with respect to the issue on: (a) Spelling Correction; (b) Grammar; (c) Punctuation; (d) Enhancement Suggestion; (e) Sentence Structure; and (f) Style Check?

4. Is there a significant difference between the means of the males and females with respect to the issue on: (a) Spelling Correction; (b) Grammar; (c) Punctuation; (d) Enhancement Suggestion; (e) Sentence Structure; and (f) Style Check?

5. What are the means of the writing errors of the upper and lower groups in Essay 1 - Division and Classification and Essay 2 - Causes and Effects?

6. Is there a significant difference in the writing errors between the upper and lower groups? What caused the significance, if any?

7. What are the means of the writing errors of the males and females in Essay 1 - Division and Classification and Essay 2 - Causes and Effects?

8. Is there a significant difference in the writing errors between sexes? What caused the significance, if any?

Identifying writing issues will reveal what students lack, and what they need to avoid, in writing essays. These issues could serve as their guide, and pointers to observe in writing. In addition, teachers can make use of these errors as warning devices when teaching students how to write essays.

\section{Method}

The study comprised of 122 Level 4 Foundation students divided into 60 upper group students and 62 lower group students. The distribution of the sample into male and female are 58 and 64 students, respectively. It is limited to these samples taking up courses in English Language at the English Language Centre of Ibra College of Technology. The study uses the terms 'issues' and 'errors' interchangeably as it quantifies all errors in the students' essays using an electronic enhancement platform called Grammarly. A period of five weeks was delegated to teaching and learning a Division and Classification and Causes and Effects Essays. The sixth week was the scheduled mid-semester examination was students wrote a typical five paragraph essay on the previously mentioned types of essays in exactly 80 minutes. The students with guidewords and phrases placed in a table form wrote the Division and Classification essay. On the other hand, the Causes and Effects essay is more of a free writing with only a choice of two topics for a Causes essay and Effects essay. After a one-week period of marking the essays, the upper and lower groups were identified by the overall passing percentages of each section. The first three sections with the highest passing percentages were labeled the upper group. While the last three sections with the lowest passing percentages were named the lower group. Then, the writing exam papers of the upper and lower groups were encoded over a period of one month. The process also included a first and second reading of the encoded essays to establish the accuracy of an actual copy of the exact essay written by the students. Finally, the essays of the student were uploaded into an electronic enhancement-writing platform known as Grammarly. 
The generated report from the writing platform on Spelling Correction; Grammar; Punctuation; Enhancement Suggestion; Sentence Structure; and Style Checkwere tallied and were analyzed using the Statistical Package for the Social Sciences.

\section{Results and Discussion}

Writing error categories were identified from the reports generated by the electronic enhancement-writing platform, namely, Spelling Correction, Grammar, Punctuation, Enhancement Suggestion, Sentence Structure, and Style Check. Also, specific issues per category were taken from the reports of the electronic platform, and corresponding writing error means were summarized in Table 1 to Table 6. More specifically, writing error means per specific issue according to sex and/or group membership in Essay 1, in Essay 2, or in both essays were also found in the tables. Table 1 shows that for the Spelling Correction category, most of the errors of the students were on Spelling issue with an overall mean of 12.41, and some were on Accidentally Confused Words with overall mean of 2.5. Moreover, only a few errors were on Commonly Confused Words (0.25) and Unknown Words issues (0.02).

Table 1

Writing Error Means Per Specific Issue on Spelling Correction

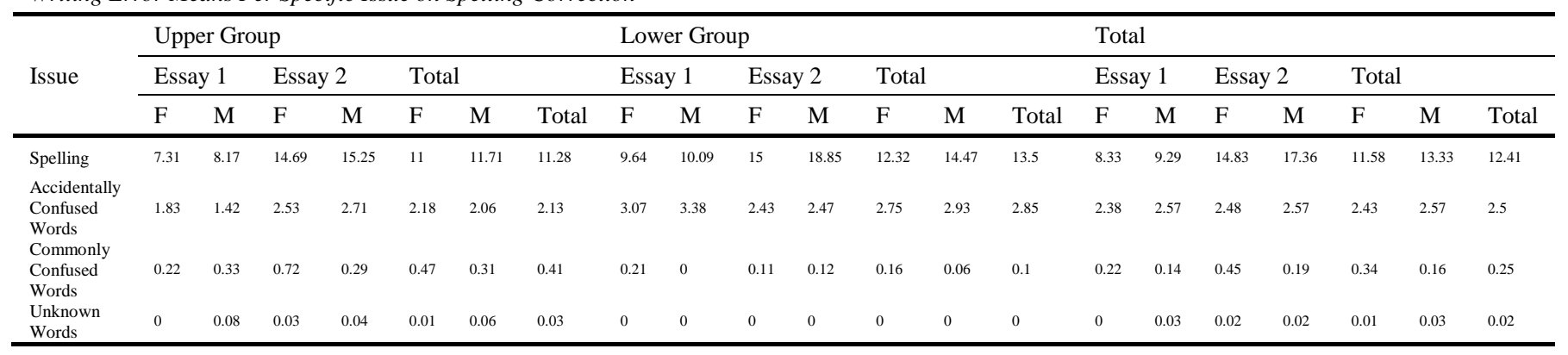

There are thirteen identified specific issues on Grammar category. Table 2 shows that only a few errors were committed under this category. However, the following are the identified specific issues according to their frequency of occurrence: Subject and Verb Agreement (1.47), Use of Articles/Determiners (1.41), Verb Form Use (1.38), Modal Verbs (0.27), Use of Nouns (0.17), Pronoun Agreement (0.1), Use of Adjectives and Adverbs(0.09), Passive Voice Use (0.09), Incorrect Use of Prepositions (0.06), Verb Agreement (0.05), Use of Qualifiers and Quantifiers (0.03), Conditional Sentences (0.01), and Use of Conjunctions (0.01).

Table 2

Writing Error Means Per Specific Issue on Grammar

\begin{tabular}{|c|c|c|c|c|c|c|c|c|c|c|c|c|c|c|c|c|c|c|c|c|c|}
\hline \multirow{3}{*}{ Issue } & \multicolumn{7}{|c|}{ Upper Group } & \multicolumn{7}{|c|}{ Lower Group } & \multicolumn{7}{|c|}{ Total } \\
\hline & \multicolumn{2}{|c|}{ Essay 1} & \multicolumn{2}{|c|}{ Essay 2} & \multicolumn{2}{|c|}{ Total } & \multirow[b]{2}{*}{ Total } & \multicolumn{2}{|c|}{ Essay 1} & \multicolumn{2}{|c|}{ Essay 2} & \multicolumn{2}{|c|}{ Total } & \multirow[b]{2}{*}{ Total } & \multicolumn{2}{|c|}{ Essay 1} & \multicolumn{2}{|c|}{ Essay 2} & \multicolumn{2}{|c|}{ Total } & \multirow[b]{2}{*}{ Total } \\
\hline & $\mathrm{F}$ & M & $\mathrm{F}$ & M & $\mathrm{F}$ & $\mathrm{M}$ & & $\mathrm{F}$ & $\mathrm{M}$ & $\mathrm{F}$ & $\mathrm{M}$ & $\mathrm{F}$ & $\mathrm{M}$ & & $\mathrm{F}$ & M & $\mathrm{F}$ & $\mathrm{M}$ & $\mathrm{F}$ & $\mathrm{M}$ & \\
\hline UseofArticles / Determiners & 1.06 & 1.08 & 2.72 & 1.54 & 1.89 & 1.31 & 1.66 & 0.54 & 0.47 & 2.43 & 1.32 & 1.48 & 0.9 & 1.16 & 0.83 & 0.72 & 2.59 & 1.41 & 1.71 & 1.07 & 1.41 \\
\hline VerbFormUse & 1.14 & 1.58 & 1.5 & 2.17 & 1.32 & 1.87 & 1.54 & 1.82 & 1.15 & 1.21 & 0.82 & 1.52 & 0.99 & 1.23 & 1.44 & 1.33 & 1.37 & 1.38 & 1.41 & 1.35 & 1.38 \\
\hline ModalVerbs & 0.56 & 0.21 & 0.42 & 0.17 & 0.49 & 0.19 & 0.37 & 0.25 & 0.35 & 0.07 & 0.06 & 0.16 & 0.21 & 0.19 & 0.42 & 0.29 & 0.27 & 0.1 & 0.34 & 0.2 & 0.27 \\
\hline SubjectandVerbAgreement & 1.36 & 1.63 & 1.47 & 1.5 & 1.42 & 1.56 & 1.48 & 2.11 & 0.82 & 1.79 & 1.32 & 1.95 & 1.07 & 1.47 & 1.69 & 1.16 & 1.61 & 1.4 & 1.65 & 1.28 & 1.47 \\
\hline IncorrectUseofPrepositions & 0.08 & 0 & 0.14 & 0.04 & 0.11 & 0.02 & 0.07 & 0.11 & 0.03 & 0.04 & 0 & 0.07 & 0.01 & 0.04 & 0.09 & 0.02 & 0.09 & 0.02 & 0.09 & 0.02 & 0.06 \\
\hline UseofNouns & 0.14 & 0.13 & 0.17 & 0.42 & 0.15 & 0.27 & 0.2 & 0.07 & 0.03 & 0.43 & 0.09 & 0.25 & 0.06 & 0.15 & 0.11 & 0.07 & 0.28 & 0.22 & 0.2 & 0.15 & 0.17 \\
\hline ConditionalSentences & 0 & 0 & 0 & 0.04 & 0 & 0.02 & 0.01 & 0 & 0 & 0.04 & 0 & 0.02 & 0 & 0.01 & 0 & 0 & 0.02 & 0.02 & 0.01 & 0.01 & 0.01 \\
\hline UseofAdjectivesandAdverbs & 0.06 & 0 & 0.14 & 0 & 0.1 & 0 & 0.06 & 0.11 & 0.06 & 0.21 & 0.09 & 0.16 & 0.07 & 0.11 & 0.08 & 0.03 & 0.17 & 0.05 & 0.13 & 0.04 & 0.09 \\
\hline PronounAgreement & 0.22 & 0 & 0.17 & 0 & 0.19 & 0 & 0.12 & 0.04 & 0.06 & 0.21 & 0.06 & 0.13 & 0.06 & 0.09 & 0.14 & 0.03 & 0.19 & 0.03 & 0.16 & 0.03 & 0.1 \\
\hline VerbAgreement & 0.03 & 0.04 & 0.06 & 0.04 & 0.04 & 0.04 & 0.04 & 0 & 0.03 & 0.04 & 0.15 & 0.02 & 0.09 & 0.06 & 0.02 & 0.03 & 0.05 & 0.1 & 0.03 & 0.07 & 0.05 \\
\hline UseofQualifiersandQuantifiers & 0.03 & 0 & 0.06 & 0.04 & 0.04 & 0.02 & 0.03 & 0.04 & 0 & 0.07 & 0.03 & 0.05 & 0.01 & 0.03 & 0.03 & 0 & 0.06 & 0.03 & 0.05 & 0.02 & 0.03 \\
\hline PassiveVoiceUse & 0 & 0 & 0.06 & 0.08 & 0.03 & 0.04 & 0.03 & 0.32 & 0.15 & 0.11 & 0 & 0.21 & 0.07 & 0.14 & 0.14 & 0.09 & 0.08 & 0.03 & 0.11 & 0.06 & 0.09 \\
\hline Useof Conjunction & 0 & 0 & 0 & 0.04 & 0 & 0.02 & 0.01 & 0 & 0 & 0 & 0.06 & 0 & 0.03 & 0.02 & 0 & 0 & 0 & 0.05 & 0 & 0.03 & 0.01 \\
\hline
\end{tabular}


On the Punctuation category, four specific issues were identified as reflected in Table 3, namely, Punctuation. Within a Clause with overall mean of 1.58, Punctuation Between Clauses (0.64), Special Character Punctuation (0.22), and Closing Punctuation (0.16).

Table 3

Writing Error Means Per Specific Issue on Punctuation

\begin{tabular}{|c|c|c|c|c|c|c|c|c|c|c|c|c|c|c|c|c|c|c|c|c|c|}
\hline \multirow{3}{*}{ Issue } & \multicolumn{7}{|c|}{ Upper Group } & \multicolumn{7}{|c|}{ Lower Group } & \multicolumn{7}{|c|}{ Total } \\
\hline & \multicolumn{2}{|c|}{ Essay 1} & \multicolumn{2}{|c|}{ Essay 2} & \multicolumn{2}{|c|}{ Total } & & \multicolumn{2}{|c|}{ Essay 1} & \multicolumn{2}{|c|}{ Essay 2} & \multicolumn{2}{|c|}{ Total } & & \multicolumn{2}{|c|}{ Essay 1} & \multicolumn{2}{|c|}{ Essay 2} & \multicolumn{2}{|c|}{ Total } & \multirow[b]{2}{*}{$\begin{array}{l}\text { Tota } \\
1 \\
\end{array}$} \\
\hline & $\mathrm{F}$ & M & $\mathrm{F}$ & M & $\mathrm{F}$ & M & $\begin{array}{l}\text { Tot } \\
\text { al }\end{array}$ & $\mathrm{F}$ & M & $\mathrm{F}$ & M & $\mathrm{F}$ & M & $\begin{array}{l}\text { To } \\
\text { tal } \\
\end{array}$ & $\mathrm{F}$ & M & $\mathrm{F}$ & M & $\mathrm{F}$ & $\mathrm{M}$ & \\
\hline $\begin{array}{l}\text { Punctuation } \\
\text { Withina } \\
\text { Clause }\end{array}$ & 1.69 & 1.63 & 1.31 & 1.13 & 1.5 & 1.37 & 1.45 & 2.36 & 1.5 & 1.86 & 1.26 & 2.11 & 1.38 & 1.71 & 1.98 & 1.55 & 1.55 & 1.21 & 1.77 & 1.38 & 1.58 \\
\hline $\begin{array}{l}\text { Punctuation } \\
\text { Between } \\
\text { Clauses }\end{array}$ & 0.42 & 0.58 & 0.83 & 0.58 & 0.63 & 0.58 & 0.61 & 0.39 & 0.44 & 1.18 & 0.68 & 0.79 & 0.56 & 0.66 & 0.41 & 0.5 & 0.98 & 0.64 & 0.7 & 0.57 & 0.64 \\
\hline $\begin{array}{l}\text { Closing } \\
\text { Punctuation }\end{array}$ & 0.08 & 0.21 & 0.25 & 0.13 & 0.17 & 0.17 & 0.17 & 0.04 & 0.06 & 0.21 & 0.26 & 0.13 & 0.16 & 0.15 & 0.06 & 0.12 & 0.23 & 0.21 & 0.15 & 0.16 & 0.16 \\
\hline $\begin{array}{l}\text { Special } \\
\text { Character } \\
\text { Punctuation }\end{array}$ & 0.14 & 0.25 & 0.22 & 0.29 & 0.18 & 0.27 & 0.22 & 0.32 & 0.26 & 0.11 & 0.21 & 0.21 & 0.24 & 0.23 & 0.22 & 0.26 & 0.17 & 0.24 & 0.2 & 0.25 & 0.22 \\
\hline
\end{tabular}

Students' writing error was also high on the Enhancement Suggestion category, in which the overall mean for the sole detected issue, the Word Choice issue, is 4.29 as shown in Table 4.

Table 4

Writing Error Means Per Specific Issue on Enhancement Suggestion

\begin{tabular}{|c|c|c|c|c|c|c|c|c|c|c|c|c|c|c|c|c|c|c|c|c|c|}
\hline \multirow{3}{*}{ Issue } & \multicolumn{7}{|c|}{ Upper Group } & \multicolumn{7}{|c|}{ Lower Group } & \multicolumn{7}{|c|}{ Total } \\
\hline & \multicolumn{2}{|c|}{ Essay 1} & \multicolumn{2}{|c|}{ Essay 2} & \multicolumn{2}{|c|}{ Total } & \multirow[b]{2}{*}{ Total } & \multicolumn{2}{|c|}{ Essay 1} & \multicolumn{2}{|c|}{ Essay 2} & \multicolumn{2}{|c|}{ Total } & \multirow[b]{2}{*}{ Total } & \multicolumn{2}{|c|}{ Essay 1} & \multicolumn{2}{|c|}{ Essay 2} & \multicolumn{2}{|c|}{ Total } & \multirow[b]{2}{*}{ Total } \\
\hline & $\mathrm{F}$ & $\mathrm{M}$ & $\mathrm{F}$ & $\mathrm{M}$ & $\mathrm{F}$ & $\mathrm{M}$ & & $\mathrm{F}$ & $\mathrm{M}$ & $\mathrm{F}$ & $\mathrm{M}$ & $\mathrm{F}$ & $\mathrm{M}$ & & $\mathrm{F}$ & $\mathrm{M}$ & $\mathrm{F}$ & $\mathrm{M}$ & $\mathrm{F}$ & $\mathrm{M}$ & \\
\hline Word Choice & 4.58 & 4.83 & 3.58 & 4.08 & 4.08 & 4.46 & 4.23 & 6.61 & 3.82 & 4.32 & 3.00 & 5.46 & 3.41 & 4.34 & 5.47 & 4.24 & 3.91 & 3.45 & 4.69 & 3.84 & 4.29 \\
\hline
\end{tabular}

However, there are less writing errors committed under the Sentence Structure category. Table 5 summarizes the three specific issues identified in this category, namely: Sentence Fragment with the overall mean of 0.81, Word Order (0.05), and Faulty Parallelism (0.05).

Table 5

Writing Error Means Per Specific Issue on Sentence Structure

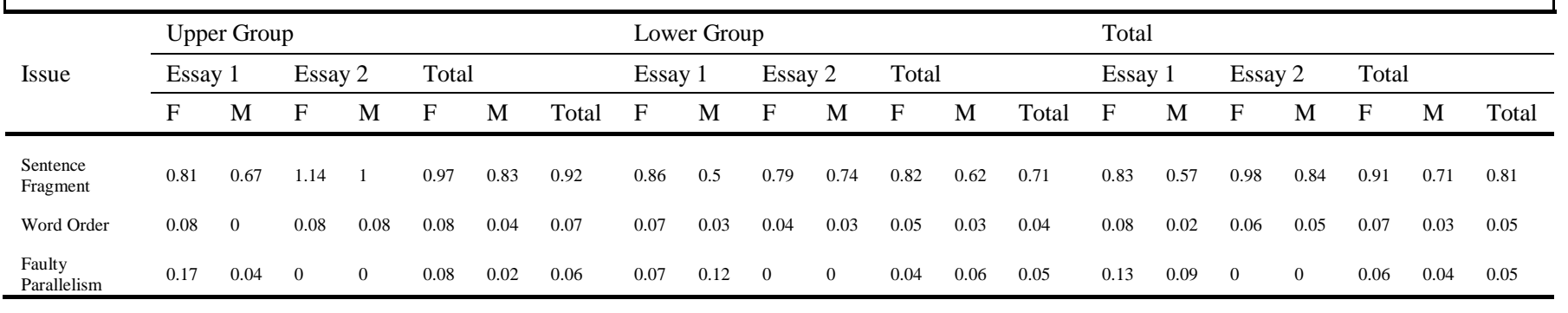

Finally, as shown in Table 6, there are three specific issues identified in the Style Check category. Most writing errors committed by the students under this category is on Improper Formatting with the overall mean of 2.18. On the other hand, only a few errors are under the issues on Wordiness (0.32) and Usage of Colloquial Speech (0.23).

Table 6

Writing Error Means Per Specific Issue on Style Check

\begin{tabular}{|c|c|c|c|c|c|c|c|c|c|c|c|c|c|c|c|c|c|c|c|c|c|}
\hline \multirow{3}{*}{ Issue } & \multicolumn{7}{|c|}{ Upper Group } & \multicolumn{7}{|c|}{ Lower Group } & \multicolumn{7}{|c|}{ Total } \\
\hline & \multicolumn{2}{|c|}{ Essay 1} & \multicolumn{2}{|c|}{ Essay 2} & \multicolumn{2}{|c|}{ Total } & & \multicolumn{2}{|c|}{ Essay 1} & \multicolumn{2}{|c|}{ Essay 2} & \multicolumn{2}{|c|}{ Total } & & \multicolumn{2}{|c|}{ Essay 1} & \multicolumn{2}{|c|}{ Essay 2} & \multicolumn{2}{|c|}{ Total } & \multirow[b]{2}{*}{$\begin{array}{l}\text { Tota } \\
1\end{array}$} \\
\hline & $\mathrm{F}$ & M & $\mathrm{F}$ & M & $\mathrm{F}$ & M & $\begin{array}{l}\text { Tot } \\
\text { al }\end{array}$ & $\mathrm{F}$ & M & $\mathrm{F}$ & M & $\mathrm{F}$ & M & $\begin{array}{l}\text { To } \\
\text { tal }\end{array}$ & $\mathrm{F}$ & M & $\mathrm{F}$ & M & $\mathrm{F}$ & M & \\
\hline $\begin{array}{l}\text { Improper } \\
\text { Formatting }\end{array}$ & 1.67 & 1.21 & 2.11 & 2.08 & 1.89 & 1.65 & 1.79 & 2.64 & 3.35 & 1.79 & 2.35 & 2.21 & 2.85 & 2.56 & 2.09 & 2.47 & 1.97 & 2.24 & 2.03 & 2.35 & 2.18 \\
\hline Wordiness & 0.11 & 0.54 & 0.36 & 0.25 & 0.24 & 0.4 & 0.3 & 0.36 & 0.26 & 0.43 & 0.29 & 0.39 & 0.28 & 0.33 & 0.22 & 0.38 & 0.39 & 0.28 & 0.3 & 0.33 & 0.32 \\
\hline $\begin{array}{l}\text { Usage of } \\
\text { Colloquial } \\
\text { Speech }\end{array}$ & 0.22 & 0.29 & 0.25 & 0.54 & 0.24 & 0.42 & 0.31 & 0.07 & 0.24 & 0.14 & 0.12 & 0.11 & 0.18 & 0.15 & 0.16 & 0.26 & 0.2 & 0.29 & 0.18 & 0.28 & 0.23 \\
\hline
\end{tabular}


The writing error per category of each respondent was quantified by adding the writing errors under the specific issues corresponding to the category. Writing error means and standard deviations per category according to sex and/or group membership in Essay 1, in Essay 1 or both essays were also calculated and shown in Table 7. For example, the writing error with respect to spelling correction in Essay 1 of the 36 females in the upper group has a mean of 9.36 and standard deviation of 6.114, while in Essay 2, the mean and standard deviation were 17.97 and 9.167, respectively. Moreover, the combined (Essay 1 and 2) writing error mean with respect to spelling correction of the females in the upper group was 13.67 and the standard deviation was 8.868. Answers for the second and fourth problem of the study were also found in Table 7 -- writing error means according to group membership and according to sex membership. For the Spelling Correction category, the writing error mean of the upper group is 13.86, and the standard deviation is 8.441, while of the lower group were 16.45 and 10.057, respectively. In the Grammar category, the mean and standard deviation of the upper group were 5.68 and 3.644, respectively, while of the lower group were 4.67 and 3.421, respectively. Also, in the Punctuation category, the mean and standard deviation of the upper group were 2.53 and 2.037, respectively, while of the lower group were 2.83 and 2.935, respectively. In the Enhancement Suggestion category, the mean and standard deviation of the upper group were 4.24 and 4.046, respectively, while of the lower group were 4.34 and 3.167, respectively. Then, in the Sentence Structure category, the mean and standard deviation of the upper group were 1.05 and 1.327, respectively, while of the lower group were 0.81 and 1.054 , respectively. Lastly, in the Style Check category, the mean and standard deviation of the upper group were 2.43 and 2.479 , respectively, while of the lower group were 3.03 and 3.213 , respectively.

On the other hand, writing error means according to sex membership were computed as follows: For the Spelling Correction category, the writing error mean of the female group is 14.35 and the standard deviation is 8.781, while of the male group were 16.09 and 9.936, respectively. In the Grammar category, the mean and standard deviation of the female group were 5.91 and 3.633, respectively, while of the male group were 4.34 and 3.305 , respectively. Also, in the Punctuation category, the mean and standard deviation of the female group were 2.92 and 2.725, respectively, while of the male group were 2.42 and 2.285, respectively. In the Enhancement Suggestion category, the mean and standard deviation of the female group were 4.7 and 4.013 , respectively, while of the male group were 3.84 and 3.083, respectively. Then, in the Sentence Structure category, the mean and standard deviation of the female group were 1.06 and 1.321 , respectively, while of the male group were 0.78 and 1.037, respectively. Lastly, in the Style Check category, the mean and standard deviation of the female group were 2.53 and 2.763 , respectively, while of the male group were 2.96 and 3.011 , respectively.

Table 7.

Descriptive Statistics of the Writing Errors per Category

\begin{tabular}{|c|c|c|c|c|c|c|c|c|c|}
\hline \multirow{2}{*}{ Writing Error Category } & \multirow{2}{*}{ Group } & \multirow{2}{*}{ Sex } & \multicolumn{3}{|l|}{ Mean } & \multicolumn{3}{|c|}{ Std. Deviation } & \multirow{2}{*}{$\mathrm{N}$} \\
\hline & & & Essay 1 & Essay 2 & Combined & Essay 1 & Essay 2 & Combined & \\
\hline \multirow{9}{*}{ Spelling Correction } & \multirow{3}{*}{ Upper Group } & Female & 9.36 & 17.97 & 13.67 & 6.114 & 9.167 & 8.868 & 36 \\
\hline & & Male & 10 & 18.29 & 14.15 & 5.54 & 7.681 & 7.839 & 24 \\
\hline & & Total & 9.62 & 18.1 & 13.86 & 5.852 & 8.536 & 8.441 & 60 \\
\hline & \multirow{3}{*}{ Lower Group } & Female & 12.93 & 17.54 & 15.23 & 6.515 & 9.98 & 8.668 & 28 \\
\hline & & Male & 13.47 & 21.44 & 17.46 & 7.411 & 12.63 & 11.034 & 34 \\
\hline & & Total & 13.23 & 19.68 & 16.45 & 6.969 & 11.585 & 10.057 & 62 \\
\hline & \multirow{3}{*}{ Total } & Female & 10.92 & 17.78 & 14.35 & 6.491 & 9.456 & 8.781 & 64 \\
\hline & & Male & 12.03 & 20.14 & 16.09 & 6.867 & 10.891 & 9.936 & 58 \\
\hline & & Total & 11.45 & 18.9 & 15.18 & 6.668 & 10.189 & 9.369 & 122 \\
\hline \multirow{9}{*}{ Grammar } & \multirow{3}{*}{ Upper Group } & Female & 4.75 & 6.97 & 5.86 & 2.719 & 4.352 & 3.773 & 36 \\
\hline & & Male & 4.75 & 6.08 & 5.42 & 2.739 & 4.01 & 3.463 & 24 \\
\hline & & Total & 4.75 & 6.62 & 5.68 & 2.704 & 4.207 & 3.644 & 60 \\
\hline & \multirow{3}{*}{ Lower Group } & Female & 5.32 & 6.64 & 5.98 & 3.465 & 3.423 & 3.477 & 28 \\
\hline & & Male & 3.15 & 4.03 & 3.59 & 2.765 & 3.176 & 2.989 & 34 \\
\hline & & Total & 4.13 & 5.21 & 4.67 & 3.262 & 3.516 & 3.421 & 62 \\
\hline & \multirow{3}{*}{ Total } & Female & 5 & 6.83 & 5.91 & 3.055 & 3.946 & 3.633 & 64 \\
\hline & & Male & 3.81 & 4.88 & 4.34 & 2.844 & 3.657 & 3.305 & 58 \\
\hline & & Total & 4.43 & 5.9 & 5.17 & 3.004 & 3.919 & 3.561 & 122 \\
\hline
\end{tabular}




\begin{tabular}{|c|c|c|c|c|c|c|c|c|c|}
\hline & & Female & 2.33 & 2.81 & 2.57 & 1.805 & 1.687 & 1.751 & 36 \\
\hline & Upper Group & Male & 2.63 & 2.33 & 2.48 & 2.584 & 2.297 & 2.423 & 24 \\
\hline & & Total & 2.45 & 2.62 & 2.53 & 2.135 & 1.949 & 2.037 & 60 \\
\hline & & Female & 3.14 & 3.61 & 3.37 & 3.913 & 3.27 & 3.581 & 28 \\
\hline Punctuation & Lower Group & Male & 2.26 & 2.5 & 2.38 & 2.02 & 2.39 & 2.199 & 34 \\
\hline & & Total & 2.66 & 3 & 2.83 & 3.03 & 2.852 & 2.935 & 62 \\
\hline & & Female & 2.69 & 3.16 & 2.92 & 2.922 & 2.515 & 2.725 & 64 \\
\hline & Total & Male & 2.41 & 2.43 & 2.42 & 2.256 & 2.333 & 2.285 & 58 \\
\hline & & Total & 2.56 & 2.81 & 2.68 & 2.619 & 2.447 & 2.533 & 122 \\
\hline & & Female & 4.61 & 3.58 & 4.1 & 5.101 & 3.459 & 4.358 & 36 \\
\hline & Upper Group & Male & 4.83 & 4.08 & 4.46 & 3.784 & 3.361 & 3.561 & 24 \\
\hline & & Total & 4.7 & 3.78 & 4.24 & 4.586 & 3.4 & 4.046 & 60 \\
\hline & & Female & 6.61 & 4.32 & 5.46 & 3.5 & 2.945 & 3.406 & 28 \\
\hline Enhancement Suggestion & Lower Group & Male & 3.82 & 3 & 3.41 & 2.736 & 2.511 & 2.639 & 34 \\
\hline & & Total & 5.08 & 3.6 & 4.34 & 3.379 & 2.773 & 3.167 & 62 \\
\hline & & Female & 5.48 & 3.91 & 4.7 & 4.55 & 3.24 & 4.013 & 64 \\
\hline & Total & Male & 4.24 & 3.45 & 3.84 & 3.219 & 2.915 & 3.083 & 58 \\
\hline & & Total & 4.89 & 3.69 & 4.29 & 4.006 & 3.086 & 3.619 & 122 \\
\hline & & Female & 1.08 & 1.22 & 1.15 & 1.204 & 1.742 & 1.489 & 36 \\
\hline & Upper Group & Male & 0.71 & 1.08 & 0.9 & 0.859 & 1.176 & 1.036 & 24 \\
\hline & & Total & 0.93 & 1.17 & 1.05 & 1.087 & 1.531 & 1.327 & 60 \\
\hline & & Female & 1 & 0.89 & 0.95 & 1.217 & 0.916 & 1.069 & 28 \\
\hline Sentence Structure & Lower Group & Male & 0.65 & 0.76 & 0.71 & 0.917 & 1.156 & 1.037 & 34 \\
\hline & & Total & 0.81 & 0.82 & 0.81 & 1.069 & 1.048 & 1.054 & 62 \\
\hline & & Female & 1.05 & 1.08 & 1.06 & 1.201 & 1.44 & 1.321 & 64 \\
\hline & Total & Male & 0.67 & 0.9 & 0.78 & 0.886 & 1.165 & 1.037 & 58 \\
\hline & & Total & 0.87 & 0.99 & 0.93 & 1.075 & 1.314 & 1.2 & 122 \\
\hline & & Female & 2.08 & 2.72 & 2.4 & 1.977 & 2.711 & 2.377 & 36 \\
\hline & Upper Group & Male & 2.04 & 2.88 & 2.46 & 2.236 & 2.997 & 2.649 & 24 \\
\hline & & Total & 2.07 & 2.78 & 2.43 & 2.066 & 2.805 & 2.479 & 60 \\
\hline & & Female & 3.07 & 2.32 & 2.7 & 3.981 & 2.195 & 3.207 & 28 \\
\hline Style Check & Lower Group & Male & 3.85 & 2.76 & 3.31 & 3.743 & 2.523 & 3.215 & 34 \\
\hline & & Total & 3.5 & 2.56 & 3.03 & 3.84 & 2.372 & 3.213 & 62 \\
\hline & & Female & 2.52 & 2.55 & 2.53 & 3.034 & 2.488 & 2.763 & 64 \\
\hline & Total & Male & 3.1 & 2.81 & 2.96 & 3.307 & 2.704 & 3.011 & 58 \\
\hline & & Total & 2.8 & 2.67 & 2.73 & 3.167 & 2.586 & 2.886 & 122 \\
\hline
\end{tabular}

The differences between groups of the writing error means per category in Essay 1 and Essay 2 and of the combined writing error means in both essays were easily determined by referring to Graph 1 . The lower group has higher combined writing error means as compared to the upper group with respect to Spelling Correction, Punctuation, Enhancement Suggestion and StyleCheck categories. However, the upper group committed higher writing error means with respect to Grammar and Sentence Structure categories. Specifically, these observations were also true in their writing errors in Essay 1 and in Essay 2, except for the means with respect to Enhancement Suggestion and with StyleCheck categories in Essay 2 wherein the upper group displayed higher writing error means than the lower group. 


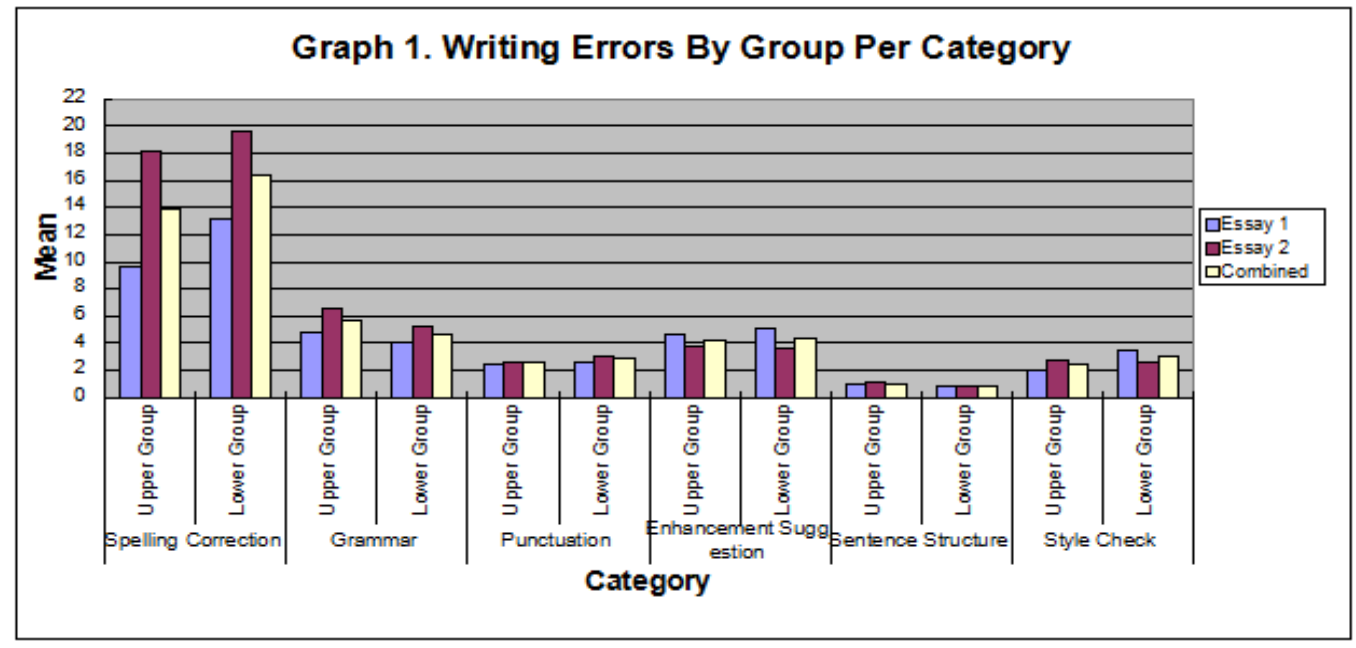

Furthermore, the differences between sexes of the writing error means per category in Essay 1 and Essay 2 and of the combined writing error means can be determined by referring to Graph 2. The female group has higher combined writing error means as compared to the male group with respect to Grammar, Punctuation, Enhancement Suggestion and Sentence Structure categories. However, the male group committed higher writing error means with respect to SpellingCorrection and StyleCheck categories. Specifically, these observations were also true in their writing errors per category in Essay 1 and Essay 2.

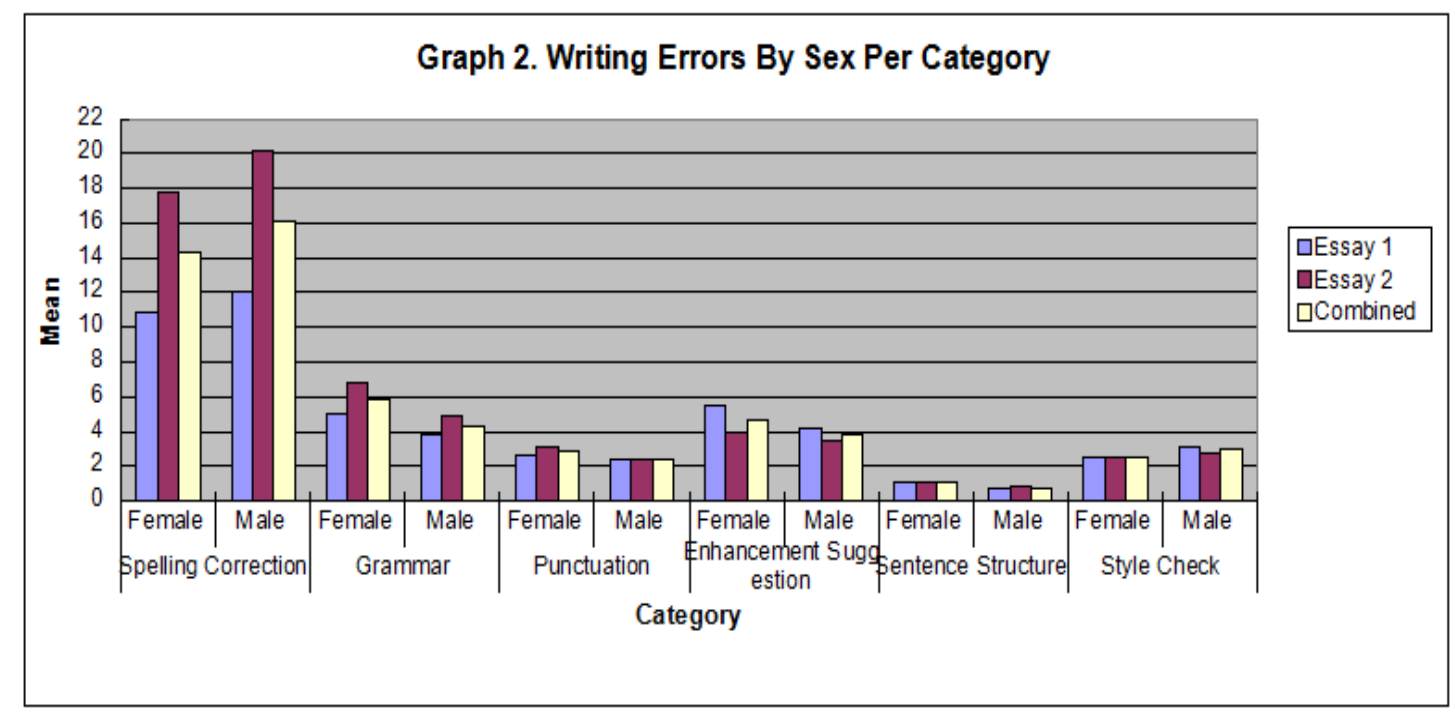

The significance of the differences in writing error means between groups and between sexes per category were tested at 0.05 level of significance by using Multivariate Analysis of Variance (MANOVA). As shown in Table 8, there are significant differences of the writing error mean between groups in Essay 1 with respect to SpellingCorrection $(\mathrm{p}$-value $=0.004, \mathrm{~F}$-value $=8.735)$ and StyleCheck $(\mathrm{p}$-value $=0.016, \mathrm{~F}$-value $=6.018)$. Moreover, significant differences between sexes were found with respect to Grammar both in Essay 1(p-value $=$ $0.045, \mathrm{~F}$-value $=6.394)$ and in Essay 2 (p-value $=0.013, \mathrm{~F}$-value $=6.394)$. However, the other differences of the writing error means per specific issue were found to be not significant as observed on their respective p-values that are greater than 0.05 .

Therefore, it can be concluded with $95 \%$ confidence level that the lower group significantly commits higher writing errors than the upper group with respect to SpellingCorrection both in Essay 1 and in Essay 2, and also with respect to StyleCheck in Essay 1. However, the upper group significantly commits higher writing error than the lower group with respect to StyleCheck in Essay 2. 
Moreover, females significantly commit higher writing error than males with respect to Grammar both in Essay 1 and in Essay 2. Furthermore, the other differences of the writing error mean per category were found to be not significant.

Table 8

Significant Difference of the Writing Error Means Per Category

\begin{tabular}{|c|c|c|c|c|c|c|c|c|c|c|c|c|}
\hline \multirow{3}{*}{ Specific Issue } & \multicolumn{6}{|l|}{ Group } & \multicolumn{6}{|l|}{ Sex } \\
\hline & \multicolumn{3}{|l|}{ Essay 1} & \multicolumn{3}{|l|}{ Essay 2} & \multicolumn{3}{|l|}{ Essay 1} & \multicolumn{3}{|c|}{ Essay 2} \\
\hline & $\mathrm{F}$ & $\mathrm{df}$ & p-val. & $\mathrm{F}$ & df & p-val. & $\mathrm{F}$ & df & p-val. & $\mathrm{F}$ & $\mathrm{df}$ & p-val. \\
\hline $\begin{array}{l}\text { Spelling } \\
\text { Correction }\end{array}$ & 8.735 & 1 & 0.004 & 0.527 & 1 & 0.469 & 0.246 & 1 & 0.621 & 1.278 & 1 & 0.261 \\
\hline Grammar & 0.926 & 1 & 0.338 & 2.961 & 1 & 0.088 & 4.114 & 1 & 0.045 & 6.394 & 1 & 0.013 \\
\hline Punctuation & 0.217 & 1 & 0.642 & 1.178 & 1 & 0.28 & 0.37 & 1 & 0.544 & 3.133 & 1 & 0.079 \\
\hline $\begin{array}{l}\text { Enhancement } \\
\text { Suggestion }\end{array}$ & 0.469 & 1 & 0.495 & 0.093 & 1 & 0.761 & 3.165 & 1 & 0.078 & 0.528 & 1 & 0.469 \\
\hline Sentence Structure & 0.135 & 1 & 0.714 & 1.797 & 1 & 0.183 & 3.43 & 1 & 0.067 & 0.305 & 1 & 0.582 \\
\hline Style Check & 6.018 & 1 & 0.016 & 0.285 & 1 & 0.595 & 0.42 & 1 & 0.518 & 0.387 & 1 & 0.535 \\
\hline
\end{tabular}

Note. Means are significantly different at $p \leq 0.05$ based on MANOVA.

The writing error of a respondent was quantified by getting the sum of the writing errors committed under the six categories, namely, Spelling Correction, Grammar, Punctuation, Enhancement Suggestion, Sentence Structure, and Style Check.Table 9 shows the descriptive statistics of the general writing errors, which includes mean, standard deviation and sample size $(\mathrm{N})$ in Essay 1, Essay 2 and both essays. For example, the writing error in Essay 1 of the 36 females in the upper group has a mean of 24.22 and standard deviation of 9.601, while in Essay 2, the mean and standard deviation were 35.28 and 10.846, respectively. Moreover, the combined (Essay 1 and 2) writing error mean of the females in the upper group was 29.75, and the standard deviation was 10.2235.

Answers for the sixth and the eighth problem of the study were also reflected in Table 9. The writing error mean of the upper group in Essay 1 and in Essay 2 were 24.52 and 3.07, respectively. While that of the lower group were 29.4 and 34.87, respectively. Moreover, the writing error mean of the female group in Essay 1 was 27.66, and in Essay 2 was 35.3. On the other hand, the male group has writing error means of 26.28 and 34.6 in Essay 1 and Essay 2, respectively.

Table 9

Descriptive Statistics of the Writing Errors (Overall Issue)

\begin{tabular}{|c|c|c|c|c|c|c|c|c|}
\hline \multirow{2}{*}{ Group } & \multirow{2}{*}{ Sex } & \multirow{2}{*}{$\begin{array}{l}\text { Mean } \\
\text { Essay1 }\end{array}$} & \multicolumn{5}{|c|}{ Std. Deviation } & \multirow{2}{*}{$\mathrm{N}$} \\
\hline & & & Essay2 & Combined & Essay1 & Essay2 & Combined & \\
\hline \multirow{3}{*}{$\begin{array}{l}\text { Upper } \\
\text { Group }\end{array}$} & Female & 24.22 & 35.28 & 29.75 & 9.601 & 10.846 & 10.2235 & 36 \\
\hline & Male & 24.96 & 34.75 & 29.855 & 8.472 & 11.848 & 10.16 & 24 \\
\hline & Total & 24.52 & 35.07 & 29.795 & 9.099 & 11.161 & 10.13 & 60 \\
\hline \multirow{3}{*}{$\begin{array}{l}\text { Lower } \\
\text { Group }\end{array}$} & Female & 32.07 & 35.32 & 33.695 & 13.01 & 12.428 & 12.719 & 28 \\
\hline & Male & 27.21 & 34.5 & 30.855 & 10.534 & 15.443 & 12.9885 & 34 \\
\hline & Total & 29.4 & 34.87 & 32.135 & 11.87 & 14.055 & 12.9625 & 62 \\
\hline \multirow{3}{*}{ Total } & Female & 27.66 & 35.3 & 31.48 & 11.796 & 11.469 & 11.6325 & 64 \\
\hline & Male & 26.28 & 34.6 & 30.44 & 9.718 & 13.955 & 11.8365 & 58 \\
\hline & Total & 27 & 34.97 & 30.985 & 10.836 & 12.663 & 11.7495 & 122 \\
\hline
\end{tabular}

The differences between groups and between sexes of the writing error mean in Essay 1 and Essay 2 and of the combined writing error means were easily determined by referring to Graph 3. The lower group has a higher combined (Essay 1 and 2) writing error mean as compared to the upper group. 
Specifically, this is also true in their writing errors in Essay 1. However, the writing error means between groups in Essay 2 were almost equal. On the other hand, the females have a bit higher writing error means than the males in Essay 1 and Essay 2. Thus, the combined (Essay 1 and 2) writing error means of the females was a bit higher than the males.

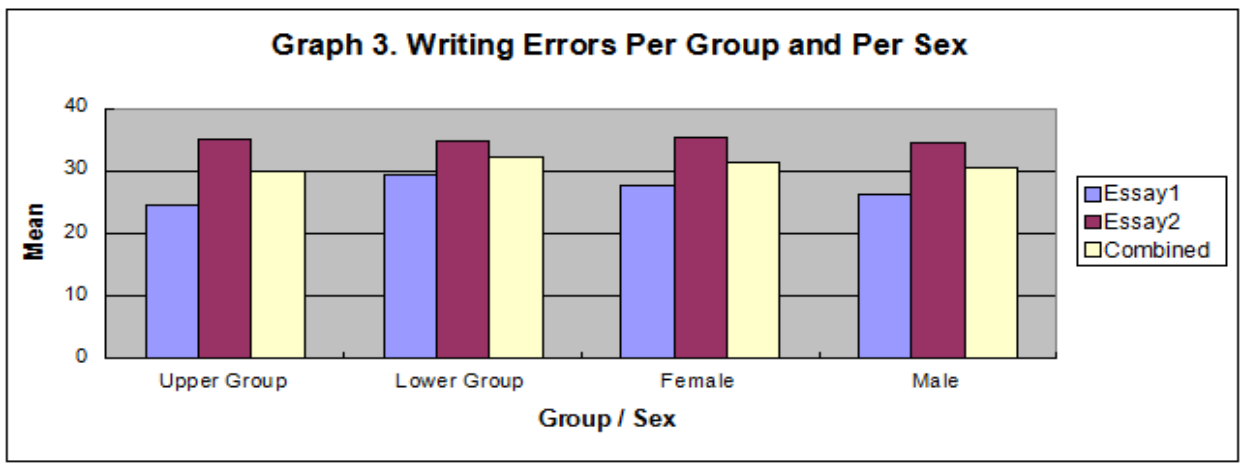

The significance of the differences in writing error means were tested at 0.05 level of significance by using Multivariate Analysis of Variance (MANOVA). As shown in Table 10, there is a significant difference in the writing errors between groups ( $\mathrm{p}$-value $=0.016$, Wilks' lambda $=0.931$ ). This is specifically brought by the significant difference between groups of the writing errors in Essay 1 ( $\mathrm{p}$-value $=0.01, \mathrm{~F}$-value $=6.819$ ). On the other hand, there is no significant difference in the writing errors in Essay 2 between groups with p-value of 0.965, which is greater than 0.05. Moreover, there are no significant differences between sexes both in Essay 1 and in Essay 2 with p-values equal to 0.288 and 0.775, respectively. Thus, we also say that, in general, there is no significant difference in the writing errors between sexes ( $\mathrm{p}$-value $=0.557$, Wilks' lambda $=0.99$ ).

Thus, it can be concluded at $95 \%$ confidence level that the lower group commits higher writing errors than the upper group. This significant difference was contributed by the results in Essay 1. Specifically, the lower group commits higher writing errors in Essay 1 than the upper group. Moreover, no significant differences in the writing errors were found between sexes.

Table 10

Significant Difference of the Writing Error Means

\begin{tabular}{llllllll}
\hline & F-value & & & & & \\
& Essay 1 & Essay 2 & df & & p-value & & Wilks' Lambda \\
Group & 6.819 & 0.002 & 1 & 0.01 & 0.965 & 0.016 & 0.931 \\
Sex & 1.141 & 0.082 & 1 & 0.288 & 0.775 & 0.557 & 0.99 \\
\hline
\end{tabular}

Note. Means are significantly different at $p \leq 0.05$ based on MANOVA.

\section{Conclusion}

The study discovered that according to the six categories, students' errors are ranked as follows: Enhancement Suggestion, Spelling Correction, Style Check, Punctuation, Grammar, and Sentence Structure. The students' number one specific error per category is Spelling, Word Choice, Improper Formatting, Punctuation within a Clause, Subject and Verb Agreement, and Sentence Fragment. The top ten specific errors across categories are Spelling, Word Choice, Accidentally Confused Words, Improper Formatting, Punctuation within a Clause, Subject and Verb Agreement, Verb Form Use, Sentence Fragment, Punctuation between Clauses, and Wordiness. In general, there is a significant difference between groups of the writing errors in Essay 1. However, there is no significant difference in the writing errors in Essay 2 between groups. Moreover, there is no significant difference in the writing errors between sexes. In addition, the lower group commits higher writing errors than the upper group. The study helps in raising awareness, among the students, of the writing errors that they need to correct. 
It also helps provide the teachers with a target on what should be given emphasis in teaching students to write excellent essays. This study also suggests that the institution must provide intensive remedial classes focusing on the improvement of the common errors of the students.

\section{References}

Abusaeedi, R. et al. (2015) A quantitative analysis of Iranian EFL learners' sources of written errors.Retrievedfrom:http://www.consortiacademia.org/index.php/ijrsll/article/viewFile/682/353

Bazerman, C., Little, J. et al. (2005). Reference Guide to Writing Across the Curriculum. West Lafayette, Ind., Parlor Press: WAC Clearinghouse.

Chan, A.Y. (2010) Toward a taxonomy of written errors: investigating into the written errors of Hong Kong Cantonese ESL learners. Retrieved from:http://202.116.197.15/cad alcanton/Fulltex t/20915_2014317_103645_31.pdf

Chkotau, M. (2011) Foreign language learners' errors and error correction in writing class.

Retrieved from:http://journal.ibsu.edu.ge/index.php/sje/article/view/218

Conner, C. (2012). "I Don't Tolerate Poor Grammar". Forbes. Forbes publishing. pp. 1-2. Retrieved December 24, 2012.

Damiani,M.F., Alves, C.V.P., Frison, L.M.B., \& Machado, R.F. (2011). Diagnosis and analysis of academic writing problems of students of pedagogy. Language and Teaching Journal, 14, (2), 455-478.

Darus, S. and Ching, K.H. (2009) Common errors in written English essays of form one Chinese students: a case study. Retrieved from:https://www.academia.edu/368278/Common_Errors_in_Written_English_Essays_of_Form One_Chinese_Students_A_Case_Study

Dysthe, O., Hertzberg, F. \&Hoel, T. L. (2010). Skrive for å lære: SkrivingihøyereUtdanning. Oslo: Abstrakt.

Evensen, L.S. (2006). Hvordanservipåutviklingavskrivekompetanser? In Matre, S. (ed.), Utfordringer for skriveopplæringogskriveforskningi dag (pp. 14-23). Trondheim: Tapir.

"Grammarly.com WHOIS, DNS, \& Domain Info - DomainTools". WHOIS. Retrieved 2016-08-27.

"Grammarly - Review". TopTenReviews. Archived from the original on January 30, 2013. Retrieved December 24, 2012.

Harmer, J. (Ed.). (2007). How to teach writing (5th ed.). Person Education Limited.

Hourani, T.M. (2008) An analysis of the common grammatical errors in the English writing made by $3^{\text {rd }}$ secondary male students in the Eastern Coast of the UAE. Retrieved from:http://bspace.buid.ac. ae/bitstream/ 1234/225/1/20050055.pdf

Kepes, B. (2015). "Checking Grammar, On The Fly And On The Cloud". Forbes. Retrieved 2018-05-17.

Khansir, A.A. et al. (2013)The study of errors in paragraph writing on Iranian EFL students. Retrieved from: http://www.idosi.org/mejsr/mejsr16\%282\%2913/10.pdf

Koroglu, Z. C. (2014) An analysis of grammatical errors of Turkish EFL students' written texts. Retrieved from :http://www.turkishstudies.net/Makaleler/374851580_8\%C3\%87etinK\%C3\%B6ro\%C4\%9FluZeynep-edb-101111.pdf

Kuar, K. and Singh, G. (2013) Errors in formal letter writing among undergraduate students. Retrieved from :http://www.melta.org.my/ET/2013/112\%20Kulwinderkaur.pdf

Langer, J. A. and Applebee, A. N. (1987). How Writing Shapes Thinking: A Study of Teaching and Learning. "Urbana, Ill": National Council of Teacher of English.

Lee, C. (2012). "English again in New Year's resolution?". The Korea Times. Archived from the original on January 27, 2013. Retrieved December 24, 2012.

Manchón, R. (2011a). Situating the Learning-to-Write and Writing-to-Learn Dimensions of L2 Writing. In Manchón, R. (2011c),(pp. 3-14).

Moore, B. (2018). "Grammarly". PCMAG. Retrieved 2018-05-16.

Don Tennant. "How Cloud Power Is Improving Written English". Grammarly.RetrievedJanuary 29, 2018.

Padmanabhan, G. (2011). "Cool tool". The Hindu. The Hindu Group. Archived from the original on January 19, 2013. Retrieved December 24, 2012.

Reid, J. \& Kroll, B. (1995). Designing and Assessing Effective Classroom Writing Assignments for NES and ESL Students. Journal of Second Language Writing, 4(1), 17- 41.

Sattayatham, A. and Ratanapinyowong, P. (2008) Analysis of errors in paragraph writing in English by first year medical students from the four medical schools at Mahidol University. Retrieved from :

Thaiss, C. (2001). Theory in WAC: Where Have We Been, Where Are We Going? In McLeod, S. H., Miraglia, E, Soven, M. \&Thaiss, C. (eds.). WAC for the New Millennium: Strategies for Continuing Writing-Across-the-Curriculum Programs. (pp. 299-325). Urbana, Il: National Council of Teachers of English.

Uhrikova, D. (2011) On some common errors in Slovak ESL/EFL writing. Retrieved from :file:///C:/Users/User/Downloads/SVOK_On\%20Some\% 20Common\%20Errors _Dominika\%20 Uhrikova _2mpANTA\%20(1).pdf 